\title{
DISCRIMINATION OF TOMATO PLANTS (SOLANUM LYCOPERSICUM) GROWN UNDER ANAEROBIC BAFFLED REACTOR EFFLUENT, NITRIFIED URINE CONCENTRATE AND COMMERCIAL HYDROPONIC FERTILIZER REGIMES USING MULTI-SOURCE SATELLITE DATA
}

\author{
Sibanda $\mathrm{M}^{1 *}$, Mutanga $\mathrm{O}^{1}$, L S Magwaza ${ }^{2}$, T Dube ${ }^{4}, \mathrm{~S}$ T. Magwaza ${ }^{2}$, A O. Odindo 3, A Mditshwa ${ }^{3}$ and P L Mafongoya ${ }^{5}$ \\ ${ }^{1}$ Discipline of Geography, School of Agricultural, Earth and Environmental Sciences, University of KwaZulu-Natal, P/Bag X01, \\ Scottsville, Pietermaritzburg 3209, South Africa (sibandam3@ukzn.ac.za) \\ ${ }^{2}$ Discipline of Horticulture, School of Agricultural, Earth and Environmental Sciences, University of KwaZulu-Natal, P/Bag \\ X01, Scottsville, Pietermaritzburg 3209, South Africa (magwals@ukzn.ac.za) \\ ${ }^{3}$ Discipline of Crop Science, School of Agricultural, Earth and Environmental Sciences, University of \\ KwaZulu-Natal, P/Bag X01, Scottsville, Pietermaritzburg 3209, South Africa \\ ${ }^{4}$ Institute for Water Studies, Department of Earth Sciences, University of the Western Cape, Private Bag X17, \\ Bellville 7535, South Africa (tidube@uwc.ac.za) \\ ${ }^{5}$ Discipline of Rural Agronomy School of Agricultural, Earth and Environmental Sciences, University of KwaZulu-Natal, P/Bag \\ X01, Scottsville, Pietermaritzburg 3209, South Africa (Mafongoya@ukzn.ac.za)
}

\section{Commission VI, WG VI/4}

KEY WORDS: Hydroponic; Vegetation monitoring; Crop production, Landsat 9 OLI, Hyperspectral data, spectral settings

\begin{abstract}
We evaluate the detection and discriminative strength of three different satellite spectral settings, namely, HyspIRI, the forthcoming Landsat 9 and Sentinel 2-MSI, in mapping tomato (Solanum lycopersicum) plants grown under hydroponic system using humanexcreta derived materials (HEDM), namely, anaerobic baffled reactor (ABR) effluent and nitrified urine concentrate (NUC) and commercial hydroponic fertilizer mix (CHFM) as nutrient sources. Partial least squares - discriminant analysis (PLS-DA) and discriminant analysis (DA) were applied to discriminate tomatoes grown under these different nutrient sources. Results of this study showed that spectral settings of HyspIRI sensor can better discriminate tomatoes grown under different fertilizer regimes when compared to Landsat 9 OLI and Sentinel-2 MSI spectral configurations. For instance, based on DA algorithm, HyspIRI exhibited high overall accuracy of 0.99 and a kappa statistic of 0.99 whereas Landsat OLI and Sentinel-2 MSI exhibited over accuracies of 0.94 and 0.95 as well as kappa statistics of 0.79 and 0.85 , respectively. Further, the performance of DA was significantly different $(\alpha=0.05)$ from that of PLS-DA based on the MaNemar tests. Overall, the performance of HyspIRI, Landsat 9 OLI-2 and Sentinel-2 MSI data seem to bring new opportunities for crop monitoring at farm scale.
\end{abstract}

\section{INTRODUCTION}

Food shortage is a large and growing challenge in subSaharan Africa (Mabhaudhi et al. 2016, Van Ittersum et al. 2016). It is estimated that at least one out of four people are hungry and undernourished in Sub-Saharan Africa. The world Bank estimates that in the 2030, nearly 9 in 10 extremely poor people will be living in Sub-Saharan Africa (The-World-Bank 2019). This is exacerbated droughts and soil nutrients deficiencies resulting from limited fertilizer applications (Mabhaudhi et al. 2016, Van Ittersum et al. 2016). This is in turn associated with high fertilizer and food prices, amongst other factors. According to FAO (2019) the Annual food inflation in increased from 5\% in 2014 to $6 \%$ in 2018 whereas in Europe it remained stable and declined in Latin America, Asia, and Oceania. Subsequently, the improvement of crop production which leads to food security has been amongst the principal priorities required to fulfill the goals of sustainable human development as well as the African Union's Agenda 2063 (Conceição et al. 2016). Furthermore, food demand is anticipated to triple in sub-
Saharan Africa after the projected 2.5-fold increase in population increase (Van Ittersum et al. 2016). Specifically, a $60 \%$ increase in agricultural and horticultural production will be required by the increasing population in the light of diminishing water and soil nutrient resources (Nordey et al. 2017). The major concern is that current dietary transition, which is in favour of vegetables such as tomatoes amongst other crops, is projected to increase, especially in urban areas, while water and soil nutrients are on a decline.

Vegetables such as tomatoes play a critical dietary role of providing fotale, vitamin $\mathrm{A}, \mathrm{C}$ and $\mathrm{E}$ as well as antioxidants (lycopene, beta-carotene, gamma-carotene), trace elements of flavonoids, phytosterols and water-soluble vitamins important for human health (Beecher 1998). To circumvent the challenge of decreasing soil nutrients and increase the production of vegetables (tomatoes), within a small land area, efforts have been exerted towards improving soil fertility and reducing expenses associated with commercial hydroponic fertilizer mix (CHFM) through the use of anaerobic Buffled Reactor (ABR) effluents and Nitrified Urine Concentrate (NUC) both as a source of soil nutrients 
and water (Smith and Smith 2017, Busari et al. 2019). Smith and Smith (2017), for instance, noted that nitrogen recovered from wastewater supported a high increase in tomato (Solanum lycopersicum) plant canopy volume, flower and fruit production when compared to plants treated with commercial hydroponic fertilizer mix (CHFM) which contained N, P, K, Ca, Mg, and Si. Al-Hamdan, Cruise et al. (2014) in Jordan noted that treatment of tomato crop using waste water facilitated an increased their fruit size by up to $2 \mathrm{~cm}$ in diameter, and weight up to $78.7 \mathrm{~g}$ in relation to those administered with potable water in their field experiment. However, the challenge that has been lurking in the agricultural sector is the lack of comprehensive spatial explicit frameworks as well as objective criterion for crop growth and productivity monitoring. Currently, Spatially explicit information on vegetable crop growth, productivity or health status was previously measured in-situ or done through routine field surveys (Al-Lahham et al. 2003, Petropoulos et al. 2018). Despite the fact that these in-situ methods obtained plausible levels of accuracy in characterizing crops, they lacked spatial representativeness. Subsequently, there is need for spatial explicit techniques that can be operational used not only to characterize the crop areal extent, but also their physiognomies. This information can help deduce and understand crop growth and productivity patterns, which are critical in ensuring food security and coming up with well-informed intervention mechanisms, or management strategies were necessary.

Meanwhile, earth observation technologies offer spatially explicit non-destructive synoptic views, innovative and economically feasible timely spatial scale means of generating farm scale crop monitoring. For example, literature shows that remotely sensed data is robust and very sensitive to subtle vegetation traits such as those induced by different water and nutrient regimes Rajah et al. (2015) showed that hyperspectral remotely sensed data could discriminate common dry beans that were rain-fed from those that were irrigated. Lu et al. (2018) discriminated tomato crops that were infected with multi-diseases at different phonological stages using hyperspectral data. Their exhibited results a high overall classification accuracy of $100 \%$ in discriminating multi-diseases healthy, asymptomatic and late stage leaves. Above all, the advent and advancement of earth observation facilities has unveiled opportunities for assessing previously unresolved crop growth and productivity related questions linked to plant physiognomies (Petropoulos et al. 2018). Despite Hyperspectral data trade-off between cost and accuracy, it remains the most accurate spatial data for monitoring crop growth and productivity. The sensor has numerous contiguous spectral channels that with the ability to detect and characterize subtle differences in plant traits when compared to other satellite data types. For example, multispectral sensors like Landsat, Satellite Pour l'Observation de la Terre (SPOT), MODerate Resolution Imaging Spectroradiometer (MODIS) are characterized with broad bands making it difficult to discern subtle plant traits as they tend to mask out critical plant information.

Despite the fact that narrow band spectral data offer optimal datasets due to the previously highlighted limitations, a number of sensors have been or are being developed with improved sensing capabilities (Transon et al. 2018). For example, the earth observation community recently witnessed the launching of Sentinel 2 multispectral imager (MSI) and Landsat 8 OLI etc. Sentinel 2 has been the first freely available sensor a set of spectral wavebands covering the red edge section of the electromagnetic spectrum (B5 $(705 \mathrm{~nm}), 6(740 \mathrm{~nm})$, and $7(783 \mathrm{~nm}))$ at a relatively fine spatial resolution of $20 \mathrm{~m}$. The sensor has a wide swath-width of $290 \mathrm{~km}$, coupled with a high spatial resolution $10 \mathrm{~m}$ as well as a five-day temporal resolution making it a better facility crop mapping and monitoring. Both sensors (i.e. Sentinel 2 MSI and Landsat 8 OLI) have been tested in various environmental application areas with plausible findings and conclusions (Dube and Mutanga 2015, Ahmadian et al. 2016, Korhonen et al. 2017, Shoko and Mutanga 2017). However, in some instances they have been reported to experience challenges, especially when applied at farm level monitoring. This has been attributed to the presence of broad wavebands which wavebands, which are perceived to be concealing most important information. As a result, now new sensors such as the proposed Landsat 9 OLI-2 (with improved noise-to-signal ratio), EnMAP and HysPIRI are being developed. The National Aeronautics and Space Administration agency (NASA) is looking forward to launching the state-of-the art Hyperspectral Infrared Imager (HyspIRI) instruments covering the visible and near-infrared section (Vis/NIR) as well as the thermal infrared (TIR). Although these sensors are earmarked for improving on the limitations of the some of the aforementioned sensors, Landsat 8 OLI will not cover some useful portions of the electromagnetic spectrum (red edge) which is instrumental in crop mapping and monitoring. There is a need to evaluate their performance in discriminating subtle vegetation properties in relation to the available broad-band multispectral sensors.

Forthcoming hyperspectral instruments have a potential to supply the much-needed spatially explicit accurate, consistent, information on vegetable crops. Both of these instruments will be spectrometric, covering the spectral ranges of $420-2450 \mathrm{~nm}$ and $380-2510 \mathrm{~nm}$ at different sampling distances of $6.5 \mathrm{~nm}$ for EnMAP's VNIR and 10nm for EnMAP's SWIR section as well as HyspIRI's VSWIR (Guanter et al. 2015, Lee et al. 2015). The swath width of HyspIRI will be $185 \mathrm{~km}$ at 30 and $60 \mathrm{~m}$ spatial resolutions whereas EnMAP have $30 \mathrm{~km}$-wide coverage across-track at a ground-sampling unit of $30 \mathrm{~m}$. The temporal resolution of EnMAP will be 4 days at the equator whereas that of HyspIRI will be 5 days. The fine spectral, spatial and temporal resolutions of these sensors make them relatively more suitable for agricultural applications. The major advantage with such instruments is that they will avail quality data at relatively low costs for data scarce regions such as the sub-Saharan Africa where resources are limited. This study therefore, sought to compare the strength of HyspIRI's spectral configuration in relation to Landsat 9 OLI-2 and Sentinel 2 MSI spectral settings in characterizing tomato (Solanum lycopersicum) crops grown under commercial hydroponic fertilizer mix, anaerobic buffled reactor effluent and nitrified urine concentrate as nutrient sources. 


\section{METHODS AND MATERIALS}

\subsection{Experimental setup}

A pot experiment was conducted in a hydroponic system that was set up in a polyethylene tunnel located at NewlandsMashu Research Station under eThekwini Municipality, Durban, South Africa (29 46' 25.648"E 30 58' 28.329" S). The hydroponic system was designed to run three nutrients streams namely, anaerobic baffle reactor (ABR) effluents, nitrified urine concentrate (NUC) and commercial hydroponic fertilizer mix (CHFM) as a control. Each hydroponic system consisted of $150 \mathrm{~L}$ tank and the nutrient solution for each system was enclosed in a $100 \mathrm{~L}$ container stacked on the ground at the foot of each system.

Six weeks old, seedlings of 'Monica', a determinate tomato cultivar purchased from a local nursery (Sunshine seedlings, Pietermaritzburg, South Africa) were transplanted to $30 \mathrm{~cm}$ polyethylene pots filled with pine sawdust as a growing medium. The nutrient solution for each nutrient source was supplied to the plants using a pressure pump (DAB Model K30/70M, DAB Pumps, MarcoPolo, Mestrino, Italy) via a $20 \mathrm{~m}$ irrigation line. A $20 \mathrm{~cm}$ drip irrigation emitters (2 L) were placed and irrigation was performed at six intervals of $5 \mathrm{~min} /$ duration daily using a timer. The study was arranged using a complete randomised design with three replications of five plants each, giving fifteen experimental units per nutrient source.

Tomato plants of the control treatment were irrigated with a commercial hydroponic fertilizer mix (Hygroponic $\AA$ and Solu-cal $\left.{ }^{\circledR}\right)$ at the rate of $800 \mathrm{~g}+620 \mathrm{~g} / 1000 \mathrm{~L}$ of water as recommended for hydroponic tomato production; NUC, commercial fertilizer application rate was used as a standard as recommended by Jonsson et al (2004), and ABR effluents with no specified application rate. For the CHFM and NUC treatment, the fertilizer was mixed using municipal tap water whereas for the ABR treatment, only effluent from the anaerobic baffle reactor component was used as nutrient and irrigation source. The experiment was allowed to run for 12 weeks before the crop was harvested. Remote sensing spectral data was collected at vegetative stage (i.e. four weeks after transplanting) and two weeks after flowering.

\subsection{Remotely sensed data}

The Analytic Spectral Device (ASD) FieldSpec instrument was used to acquire the spectral reflectance of tomatoes plants receiving ABR effluents, NUC and CHFM. The spectral data was collected on The ASD measured the radiation at 1.4 intervals for the $350-1000 \mathrm{~nm}$ and $2 \mathrm{~nm}$ intervals for the $1000-2500 \mathrm{~nm}$ spectral regions. The reflectance measurements were conducted using bare fibreoptic held at nadir position $\sim 0.5 \mathrm{~m}$ above the tomato canopies resulting in a field of view with a diameter of $\sim 0.225 \mathrm{~m}$. This diameter was found to be adequate to capture the reflectance of the tomato canopies. The normalization of spectral measurements was conducted after every 5 to 10 spectral measurements, using a standard spectralon. This was done to circumvent the possible changes in weather conditions as well as irradiance from the sun (Abdel-Rahman et al. 2014). The spectral measurements were conducted under clear skies during the day between $10 \mathrm{~h} 00$ and $14 \mathrm{~h} 00$ since this is the time with maximum net radiation. A total of 90 spectral samples were measured on canopies of tomatoes treated with CHFM $(n=30)$, ABR $(n=30)$ and NUC $(n=30)$. In capturing each spectral sample, the instrument recorded radiance of tomato crops 10 times and then provided an average.

\subsection{Discriminating tomato plants grown under different fertilizer regimes}

Exploratory data analysis was conducted to determine if the data followed a normal distribution curve. Normality test was performed using the Kolmogorov Smirnov test. Further, we assessed spectral separability as well as administered a pre-filter (Adelabu et al. 2014) after hyperspectral data resampling it to HyspIRI, Sentinel-2 MSI and Landsat 8/9 OLI spectral configurations. Resampling was based on the Analysis of Variance test (ANOVA). We then conducted post-hoc test to establish the channels that exhibited significant differences between the spectral data of the tomatoes crops receiving nutrients from ABR effluent, NUC and CHFM.

The other objective of this study was to assess the accuracies of partial least squares discriminant analysis and Discriminant Analysis algorithms in characterizing tomato crops grown under the three fertilizer regimes. In that regard, we used the PLSDA and the DA to classify the spectral reflectance of tomato crops growing under UNC, UNF and ABR fertilizer treatments. Details about DA and PLS DA are provided in Zhang et al. (2012) and Boulesteix (2004). Prior to conducting PLS-DA and DA, the spectral samples were partitioned into training $(70 \%)$ and testing $(30 \%)$ data. The 30 percent of the samples were used in model accuracy assessment. Specifically, we further computed the overall, producer and user accuracies, as well as the kappa statistics for each set of spectral settings as classified by the two algorithms. To compare the performance of the two algorithms, a McNemar's test was conducted as detailed by Manandhar et al. (2009) and de Leeuw et al. (2006).

\section{RESULTS}

Normality test resulted showed significant differences between tomato plants treated with different fertilizer combinations based on the spectral settings of HyspIRI, Sentinel-2MSI and Landsat 8/9 OLI (Figure 2). For HyspIRI resampled data, significant differences were observed in the visible, NIR as well as the SWIR portions of the electromagnetic spectrum. Most glaring differences were observed in the NIR portion of the electromagnetic spectrum as illustrated on Figure 2 (a). 

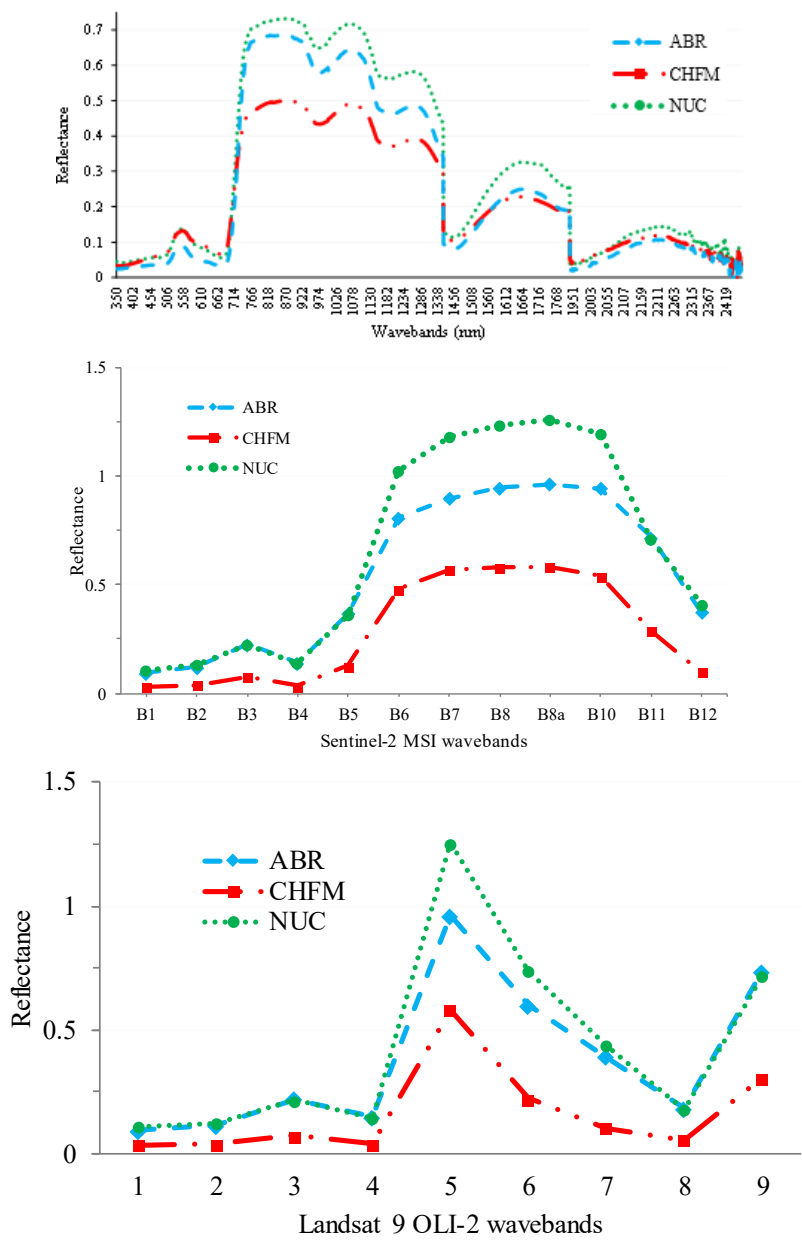

Figure 2: Mean spectral variability of tomatoes under ABR effluent, NUC and CHFM treatments.

\subsection{Discriminating Tomatoes under ABR effluent, NUC and CHFM}

All sensors better characterized tomato crops administered with ABR when compared to those administered with CHFM and NUC. Specifically, high producer and user accuracies ranging between 91 to $100 \%$ were observed in characterizing tomatoes treated with ABR (Table 2). Meanwhile tomatoes administered with ABR and CHFM were characterized with slightly lower accuracies (Table 2). Moreover, HyspIRI, produced high accuracies characterized by kappa statistics of 0.99 , whereas the spectral settings of Sentinel-2 MSI and Landsat 9 OLI-2's spectral settings exhibited kappa statistics of 0.85 and 0.79 , respectively. HyspIRI spectral settings exhibited high producer accuracies of 100,92 and $100 \%$ for ABR, CHFM and NUC respectively. Meanwhile resulted in Sentinel-2 MSI exhibited slightly lower producer accuracies $(A B R=91 \%$, $\mathrm{CHFM}=86$ and $\mathrm{NUC}=100 \%)$. Landsat OLI-2 exhibited producer that were comparable to those of Sentinel 2 MSI which were 91 for ABR, 83 for CHFM and 100 for NUC. The same trend could be observed on the user accuracies (Table 2)

\subsection{Performance of DA and PLS-DA algorithms in discriminating Tomatoes under ABR effluent, NUC and CHFM}

When comparing the performance of algorithms, DA exhibited very high accuracies. For instance, DA's the producer accuracies derived using DA across all fertilizer treatments and sensor simulations ranged from a minimum of $89 \%$ whereas PLS-DA had slightly lower minimum of $83 \%$ (Table 2). The user accuracies derived using DA ranged from a minimum of $76 \%$ whereas those derived using PLSDA ranged from $65 \%$ to 100 . The overall accuracies derived using DA were higher (i.e. 0.94-0.99) when compared to those derived using PLS-DA (i.e. 0.3-0.97). Uniformly, the kappa statistics derived using DA were higher ranging between 0.79 and 0.99 whereas those derived using PLS-DA were lower ranging between 0.63 to 0.90 (Table 2).

Table 2: Classification accuracies derived using HyspIRI, Sentinel 2 MSI and Lands 9 OLI-2 spectral settings

\begin{tabular}{|c|c|c|c|c|c|c|c|c|c|}
\hline \multirow[t]{2}{*}{ Sensor } & & \multicolumn{2}{|l|}{ PLS-DA } & \multicolumn{2}{|l|}{ DA } & \multicolumn{2}{|l|}{ PLS-DA } & \multicolumn{2}{|l|}{ DA } \\
\hline & & $\mathrm{PA}$ & UA & PA & UA & $\mathrm{OA}$ & Kappa & $\mathrm{OA}$ & Kappa \\
\hline \multirow{3}{*}{ HyspIRI } & $\mathrm{ABR}$ & 100 & 95 & 100 & 100 & 0.97 & 0.90 & 0.99 & 0.99 \\
\hline & CHFM & 92 & 100 & 100 & 100 & & & & \\
\hline & NUC & 100 & 94 & 100 & 100 & & & & \\
\hline \multirow[t]{3}{*}{ Sentinel 2 MSI } & ABR & 91 & 100 & 100 & 100 & 0.90 & 0.69 & 0.95 & 0.85 \\
\hline & CHFM & 86 & 100 & 89 & 100 & & & & \\
\hline & NUC & 100 & 65 & 100 & 82 & & & & \\
\hline \multirow[t]{3}{*}{ Landsat 9 OLI-2 } & $\mathrm{ABR}$ & 91 & 95 & 95 & 100 & 0.89 & 0.63 & 0.94 & 0.79 \\
\hline & CHFM & 83 & 100 & 89 & 100 & & & & \\
\hline & NUC & 100 & 65 & 100 & 76 & & & & \\
\hline
\end{tabular}




\section{DISCUSSION}

We sought to compare the strength of HyspIRI's spectral configuration in relation to Landsat 9 OLI-2 and Sentinel 2 MSI spectral settings in characterizing tomato (Solanum lycopersicum) crops grown under CHFM, ABR and NUC treatment regimes. Results of this study showed that tomatoes that were fertilized using ABR could be optimally discriminated (i.e. Kappa statics ranging 0.79 to 0.99 ) from those that were administered with CHFM and NUC. This could be attributed to the fact that ABR effluents have nutrient properties favorable for tomato plants, which facilitate excessive vegetative growth, high biomass accumulation, delayed or uneven maturity (Maurer et al. 1995, Zavadil 2009, Pedrero et al. 2010). Tomato crops with excessive vegetative growth, high biomass accumulation, delayed or uneven maturity tend to be easily detected and discriminated by satellite sensors compared to those which are not. These tend to make tomatoes growing under the $\mathrm{ABR}$ treatments to have a different spectral signature from those that are fertilized using CHFM and NUC. Literature illustrates that $\mathrm{ABR}$ tends to facilitate high biomass accumulation (i.e. increased leaf area index) hence the high classification accuracies exhibited by all remotely sensed data in this study (Maurer et al. 1995, Al-Lahham et al. 2003, Zavadil 2009). For example, Al-Lahham et al. (2003) illustrated that tomato crops that were administered with high quantities of waste water had big fruit sizes hence high biomass accumulation in relation to those that were administered with portable water. In a related study, Zavadil (2009) noted that primary treated waste water contained an average of 14-fold nitrogen amounts $(70.6 \mathrm{mg} / \mathrm{l}$, which was $89 \%$ ammonia form), which also was 3 -fold of the total phosphorus which resulted in high yields and therefore biomass accumulation of lettuce salad, radishes, and carrots vegetables in their study of assessing the influence of sewage water on vegetables. Subsequently, the increases in biomass accumulation associated with wastewater treated vegetables could explain the discrimination of $\mathrm{ABR}$ treated tomato crops from those administered with CHFM and NUC.

When assessing the performance of sensors, HyspIRI outperformed the two multispectral sensors namely, Sentinel-2 MSI and Landsat OLI spectral settings in discriminating tomato crops grown under different fertilizer regimes. This could be explained that HyspIRI is a hyperspectral sensor characterized by narrow spectral wavebands that are more sensitive to the spectral reflectance of tomato crops grown under different fertilizer regimes than broad band sensor settings such as those of Landsat which could be masking out those minute tomato crops spectral variations. There is consistently growing body of literature that supports the claim that hyperspectral sensors are more sensitive to minute vegetation spectral variabilities compared to broad band sensors due to the narrowed bandwidths confugeration (Thenkabail et al. 2002, Thenkabail et al. 2004, Adam et al. 2010, Mansour et al. 2012, Thenkabail and Lyon 2016, Thenkabail 2017). Specifically, Thenkabail et al. (2002) illustrated that narrow bands characterized different crop traits such as yield as well as spectral variations when compared to broadband spectral data. For example, Thenkabail et al. (2002) were able to better characterize wheat from barley using hyperspectral. They attributed this to the variation in spectral settings (bandwidths) of the sensors they used. These spectral variations affected the detail that will determines the accuracy of the models for plant trait characterization. Meanwhile, Clark (2017) noted that there was no significant variation in the performance of HyspIRI and Sentinel-2 MSI as well as Landsat OLI in landcover classification of the San Francisco Bay Area in northern California, USA. However, their results confirmed that HyspIRI exhibited higher classification accuracies in their study.

Results of this study illustrated that Sentinel 2 MSI and Landsat 9 performed satisfactorily in discriminating tomatoes grown under different fertilizer regimes, although Sentinel 2 MSI outperformed Landsat OLI. This could be explained by the fact that Sentinel-2 MSI spectral settings cover the red edge portion of the electromagnetic spectrum which is critical in mapping and detecting various vegetation traits. Also there is a large and on-growing body of literature that has illustrated that Sentinel-2 MSI performs better than Landsat OLI in vegetation mapping (Clark 2017, Colkesen and Kavzoglu 2017, Shoko and Mutanga 2017). The study by Colkesen and Kavzoglu (2017) illustrated that Sentinel-2 MSI outperformed Landsat OLI in discriminating alfalfa, sugar beet and bean in the agricultural lands of the Ferizli district, Turkey. Shoko and Mutanga (2017) also illustrated the robustness of Sentinel-2 MSI remotely sensed data in better discriminating C3 Festuca costata from the C4 Themeda triandra grasses in a mountainous area in South Africa. They also attributed the optimal performance of Sentinel-2 MSI to the presence of red edge bands in discriminating Festuca from Themeda grasses.

Although this was not the major objective of the study, DA outperformed PLS-DA in discriminating tomato crops grown under different fertilizer regimes. In this study PLSDA failed to derive unnecessary variables for characterizing tomato crops grown under different fertilizer regimes. On the other hand, there are numerous studies that have illustrated the optimal performance of DA in dimension reduction as well as feature extraction (Filella et al. 1995, Karimi et al. 2005, Pu and Liu 2011).

\section{CONCLUSION}

The prime objective of this study was to compare the strength of the forthcoming hyperspectral sensor HyspIRI's spectral settings in the context of characterizing the effects of different fertilizer treatment regimes on tomatoes crops. Furthermore, the study assessed the performance of PLS-DA in relation to DA in discriminating tomatoes treated with ABR, NUC and CHFM. Grounded on the results exhibited by this study we conclude that:

- The forthcoming HyspIRI, sensor has the potential to accurately map tomato crops under various fertilizer regimes.

Landsat and Sentinel comparable performed to HyspIRI spectral settings. 
- DA offers optimal accuracies in characterizing tomatoes grown under different fertilizer regimes when compared to PLS-DA.

These findings are a substantial foundation upon which comprehensive precision agricultural assessments initiatives could be formed. These initiatives are required in order to attain sustainable agriculture as well as food security in regions such as sub Saharan Africa where agricultural crop monitoring is currently hindered by the limited access to robust spatial data sets.

\section{ACKNOWLEDGEMENTS}

The University of KwaZulu-Natal (UKZN), College of Agriculture, Engineering and Sciences and the National Research Foundation (NRF) of South Africa are acknowledged for financial support of this study. The pollution research group (PRG) is acknowledged for technical support and for providing human-excreta derived materials as well as space for experimentation for this study. We also extend our gratitude to the anonymous reviewers for their constructive criticism.

\section{REFERENCES}

Abdel-Rahman, E. M., O. Mutanga, J. Odindi, E. Adam, A. Odindo and R. Ismail, 2014. "A comparison of partial least squares (PLS) and sparse PLS regressions for predicting yield of Swiss chard grown under different irrigation water sources using hyperspectral data." Computers and Electronics in Agriculture 106: 11-19.

Adam, E., O. Mutanga and D. Rugege, 2010. "Multispectral and hyperspectral remote sensing for identification and mapping of wetland vegetation: a review." Wetlands Ecology and Management 18(3): 281-296.

Adelabu, S., O. Mutanga, E. Adam and R. Sebego, 2014. "Spectral Discrimination of Insect Defoliation Levels in Mopane Woodland Using Hyperspectral Data." Selected Topics in Applied Earth Observations and Remote Sensing, IEEE Journal of 7(1): 177-186.

Ahmadian, N., S. Ghasemi, J.-P. Wigneron and R. Zölitz, 2016. "Comprehensive study of the biophysical parameters of agricultural crops based on assessing Landsat 8 OLI and Landsat 7 ETM+ vegetation indices." GIScience \& Remote Sensing 53(3): 337-359.

Al-Lahham, O., N. El Assi and M. Fayyad, 2003. "Impact of treated wastewater irrigation on quality attributes and contamination of tomato fruit." Agricultural Water Management 61(1): 51-62.

Beecher, G. R., 1998. "Nutrient content of tomatoes and tomato products." Proceedings of the Society for Experimental Biology and Medicine 218(2): 98-100.
Boulesteix, A.-L., 2004. "PLS Dimension reduction for classification with microarray data." Statistical applications in genetics and molecular biology 3(1): 1-32.

Busari, T., A. Senzanje, A. Odindo and C. Buckley, 2019. "Evaluating the effect of irrigation water management techniques on (taro) madumbe (Colocasia esculenta (L.) Schott) grown with anaerobic filter (AF) effluent at Newlands, South Africa." Journal of Water Reuse and Desalination.

Clark, M. L., 2017. "Comparison of simulated hyperspectral HyspIRI and multispectral Landsat 8 and Sentinel-2 imagery for multi-seasonal, regional land-cover mapping." Remote Sensing of Environment 200: 311-325.

Colkesen, I. and T. Kavzoglu, 2017. "Ensemble-based canonical correlation forest (CCF) for land use and land cover classification using sentinel-2 and Landsat OLI imagery." Remote Sensing Letters 8(11): 1082-1091.

Conceição, P., S. Levine, M. Lipton and A. WarrenRodríguez, 2016. "Toward a food secure future: Ensuring food security for sustainable human development in SubSaharan Africa." Food Policy 60: 1-9.

de Leeuw, J., H. Jia, L. Yang, X. Liu, K. Schmidt and A. K. Skidmore, 2006. "Comparing accuracy assessments to infer superiority of image classification methods." International Journal of Remote Sensing 27(1): 223-232.

Dube, T. and O. Mutanga, 2015. "Evaluating the utility of the medium-spatial resolution Landsat 8 multispectral sensor in quantifying aboveground biomass in uMgeni catchment, South Africa." ISPRS Journal of Photogrammetry and Remote Sensing 101: 36-46.

FAO, 2019. Inflation in consumer price index for food, FAO, Rome, Italy

Filella, I., L. Serrano, J. Serra and J. Penuelas, 1995. "Evaluating wheat nitrogen status with canopy reflectance indices and discriminant analysis." Crop Science 35(5): 1400-1405.

Guanter, L., H. Kaufmann, K. Segl, S. Foerster, C. Rogass, S. Chabrillat, T. Kuester, A. Hollstein, G. Rossner and C. Chlebek, 2015. "The EnMAP spaceborne imaging spectroscopy mission for earth observation." Remote Sensing 7(7): 8830-8857.

Karimi, Y., S. Prasher, H. McNairn, R. Bonnell, P. Dutilleul and P. Goel, 2005. "Classification accuracy of discriminant analysis, artificial neural networks, and decision trees for weed and nitrogen stress detection in corn." Transactions of the ASAE 48(3): 1261-1268.

Korhonen, L., P. Packalen and M. Rautiainen, 2017. "Comparison of Sentinel-2 and Landsat 8 in the estimation of boreal forest canopy cover and leaf area index." Remote Sensing of Environment 195: 259-274. 
Lee, C. M., M. L. Cable, S. J. Hook, R. O. Green, S. L. Ustin, D. J. Mandl and E. M. Middleton, 2015. "An introduction to the NASA Hyperspectral InfraRed Imager (HyspIRI) mission and preparatory activities." Remote Sensing of Environment 167: 6-19.

Lu, J., R. Ehsani, Y. Shi, A. I. Castro and S. Wang, 2018. "Detection of multi-tomato leaf diseases (late blight, target and bacterial spots) in different stages by using a spectralbased sensor." Scientific reports 8(1): 2793.

Mabhaudhi, T., T. Chibarabada and A. Modi, 2016. "Waterfood-nutrition-health nexus: Linking water to improving food, nutrition and health in Sub-Saharan Africa." International journal of environmental research and public health 13(1): 107.

Manandhar, R., I. Odeh and T. Ancev, 2009. "Improving the Accuracy of Land Use and Land Cover Classification of Landsat Data Using Post-Classification Enhancement." Remote Sensing 1(3): 330-344.

Mansour, K., O. Mutanga and T. Everson, 2012. "Remote sensing based indicators of vegetation species for assessing rangeland degradation: opportunities and challenges." Afr. J. Agr. Res 7: 3261-3270.

Maurer, M. A., F. S. Davies and D. A. Graetz, 1995. "Reclaimed Wastewater Irrigation and Fertilization of MatureRedblush'Grapefruit Trees on Spodosols in Florida." Journal of the American Society for Horticultural Science 120(3): 394-402.

Nordey, T., C. Basset-Mens, H. De Bon, T. Martin, E. Déletré, S. Simon, L. Parrot, H. Despretz, J. Huat and Y. Biard, 2017. "Protected cultivation of vegetable crops in sub-Saharan Africa: Limits and prospects for smallholders. A review." Agronomy for Sustainable Development 37(6): 53.

Pedrero, F., I. Kalavrouziotis, J. J. Alarcón, P. Koukoulakis and T. Asano, 2010. "Use of treated municipal wastewater in irrigated agriculture-Review of some practices in Spain and Greece." Agricultural Water Management 97(9): 12331241 .

Petropoulos, G. P., P. K. Srivastava, M. Piles and S. Pearson, 2018. "Earth observation-based operational estimation of soil moisture and evapotranspiration for agricultural crops in support of sustainable water management." Sustainability 10(1): 181 .

$\mathrm{Pu}, \mathrm{R}$. and D. Liu, 2011. "Segmented canonical discriminant analysis of in situ hyperspectral data for identifying 13 urban tree species." International Journal of Remote Sensing 32(8): 2207-2226.

Rajah, P., J. Odindi, E. M. Abdel-Rahman, O. Mutanga and A. Modi, 2015. "Varietal discrimination of common dry bean (Phaseolus vulgaris L.) grown under different watering regimes using multitemporal hyperspectral data." Journal of Applied Remote Sensing 9(1): 096050-096050.
Shoko, C. and O. Mutanga, 2017. "Examining the strength of the newly-launched Sentinel 2 MSI sensor in detecting and discriminating subtle differences between $\mathrm{C} 3$ and $\mathrm{C} 4$ grass species." ISPRS Journal of Photogrammetry and Remote Sensing 129: 32-40.

Smith, D. P. and N. T. Smith, 2017. "Recovery of Wastewater Nitrogen for Solanum lycopersicum Propagation." Waste and Biomass Valorization: 1-12.

The-World-Bank, 2019. Poverty \& Equity Data portal. 2019, The World Bank.

Thenkabail, P. S. 2017. Hyperspectral remote sensing of vegetation: knowledge gain and knowledge gap after 50 years of research (Conference Presentation). Hyperspectral Imaging Sensors: Innovative Applications and Sensor Standards 2017, International Society for Optics and Photonics.

Thenkabail, P. S., E. A. Enclona, M. S. Ashton, C. Legg and M. J. De Dieu, 2004. "Hyperion, IKONOS, ALI, and ETM+ sensors in the study of African rainforests." Remote Sensing of Environment 90(1): 23-43.

Thenkabail, P. S. and J. G. Lyon 2016. Hyperspectral remote sensing of vegetation, CRC Press.

Thenkabail, P. S., R. B. Smith and E. De Pauw, 2002. "Evaluation of narrowband and broadband vegetation indices for determining optimal hyperspectral wavebands for agricultural crop characterization." Photogrammetric Engineering and Remote Sensing 68(6): 607-622.

Transon, J., R. d'Andrimont, A. Maugnard and P. Defourny, 2018. "Survey of hyperspectral earth observation applications from space in the sentinel-2 context." Remote Sensing 10(2): 157.

Van Ittersum, M. K., L. G. Van Bussel, J. Wolf, P. Grassini, J. Van Wart, N. Guilpart, L. Claessens, H. de Groot, K. Wiebe and D. Mason-D'Croz, 2016. "Can sub-Saharan Africa feed itself?" Proceedings of the National Academy of Sciences 113(52): 14964-14969.

Zavadil, J., 2009. "The effect of municipal wastewater irrigation on the yield and quality of vegetables and crops." Soil Water Res 4(3): 91-103.

Zhang, H., Y. Lan, C. Suh, J. Westbrook, R. Lacey and W. Hoffmann, 2012. "Differentiation of cotton from other crops at different growth stages using spectral properties and discriminant analysis." Transactions American Society of Agricultural and Biological Engineers 55: 1623-1630. 